\title{
“Ó vinde, Bacas!" \\ A expressão cênica e a escolha da tradução
}

\author{
"Come, Bachae!" \\ The scenic expression and the choice of translation
}

\author{
José Renato Mangaio Noronha \\ Universidade Federal de Santa Maria, Santa Maria, RS, Brasil
}

Resumo: A tradução de Jaa Torrano para o texto Bacas de Eurípedes propõe ao encenador contemporâneo à oportunidade de uma experiência dionisíaca a ser compreendida em um novo ambiente cultural. Ainda que seu contexto original proponha um mergulho arqueológico e antropológico sobre as tradições e manifestações do culto a Dioniso, a teatralidade contemporânea reconstrói sob novos referenciais a liturgia bacante que como pertencente a práticas culturais se modificou em seu percurso. No entanto, existe um saber iniciativo e fundamental a ser compreendido a partir do referencial enunciado pelo texto de Eurípedes e que encontra a precisão lingüística e poética em língua portuguesa no texto do professor Jaa Torrano. Tal saber desvela um conhecimento e ao mesmo tempo uma experiência com as palavras na narrativa sobre os cultos a Dioniso, requerendo assim a compreensão da linguagem escrita e do contexto cultural à que se refere. Ao mesmo tempo instiga ao artista e encenador que reconheça na experiência e na memória um caminho de compreensão mais profunda. Assim, a linguagem cênica mostra-se como caminho para a presentificação da experiência sobre o mito de Dioniso e as ações báquicas do texto. Tais ações precisam atingir o grau da performance para que se encontre a verdade sobre a representação, ou seja, o dito passe a ser concretizado pela cena como um rito para além da teatralização, o que já ocorre nas leituras de grupos e encenadores contemporâneos. O presente texto se propõe a reflexão entre a prática e a teoria no intuito de propor uma leitura cênica desta tradução.

Palavras-Chave: Teatro, tradução, linguagem, mito, religião, performance.

Abstract: Jaa Torrano's translation of Euripides' Bachae proposes to contemporary director the opportunity of a Dionysian experience to be understood in a new cultural environment. Although its original context propose an archaeological and anthropological look into the traditions and manifestations of the cult of Dionysus, contemporary theatricality recreates under new references the maenad liturgy, an experience that as belonging to cultural practices changed its artistic path. However, there is an initiatory and fundamental knowledge to be understood from the framework set out by Euripides' text, knowledge that founds linguistic and poetic precision in Portuguese language in the Jaa Torrano's version of the play. His translation reveals intellectual knowledge as much as an experimentation with words in the narrative about the cults of Dionysus, thus requiring the comprehension of written language and the cultural context to which it refers. At the same time, it excites the artist and director to recognize in the experience and in the memory a path for deeper understanding. The scenic language is shown as a path to make present the experience on Dionysian myth and the Bacchic rituals presented in the text. Such actions need to reach the level of performance to finding the truth of the representation, or, in another words, the clearance achieved by the scene as a rite of dramatization beyond what already occurs in the readings of groups and contemporary directors. This paper proposes a reflection on the practice and theory in order to propose a scenic reading of this translation.

Keywords: Theater, Translation, language, myth, religion, performance.

34 fragmentum, N. 38, Vol. 1. Laboratório Corpus: UFSM, Jul./ Set. 2013 


\section{Apresentação}

O fenômeno teatral, em sua raiz grega, propõe a celebração de Dioniso através da cena. Esta prática subsiste ainda hoje no inconsciente do espectador ou do ator. A arte teatral mantém vínculos com o culto que a originou sejam elas na máscara, no êxtase, na embriagues e na loucura apresentadas no ato teatral ${ }^{2}$.

Experiências e teorias teatrais contemporâneas revelam a sua busca pelo elo perdido do teatro ocidental com a "sacralidade" original. Artistas, grupos, pesquisadores e teóricos como Antonin Artaud, Richard Schechner, Eugênio Barba, Jerzy Grotowski, Peter Brook, Yoshii Oida, LUME Teatro propõem ou reconhecem ações em um campo que aproxima o teatro da performance ritual. Cada artista, instituição ou grupo, a sua maneira, revela uma possibilidade da retomada do sentido bacante original. Grupos teatrais contemporâneos se apropriam de elementos do "espírito da tragédia"3 e a conectam com sua própria cultura, como é o caso do grupo paulistano: Uzyna Uzona do Teatro Oficina dirigido por José Celso Martinez Correia.

Deus estrangeiro de múltiplos nomes e predicados: nasce Zagreu, filho de Zeus e Perséfone, cujo coração sobrevive à fúria dos titãs graças a Atenas, Zeus ao ingeri-lo fecunda a mortal Sêmele, filha de Cadmo e Harmonia que por ciúme e astúcia de Hera foi "partejada por relampeado fogo". Nasce Dioniso, da coxa de Zeus e cujo culto os portadores de ramo, Bacos, celebrariam.

Originário do culto a Dioniso, o Teatro Ocidental aparentemente criou uma ruptura com o pensamento mítico e se afastou do aspecto religioso presente na cultura grega, porém Dioniso penetra em outras dimensões.

Em um mundo construído dessa maneira e artificialmente protegido penetrou
então o som extático da celebração de Dioniso, no qual a inteira desmedida da
natureza se revelava ao mesmo tempo em prazer, em sofrimento e em
conhecimento. Tudo o que até agora valia como limite, como determinação de
medida, mostrou-se aqui como uma aparência artificial: a "desmedida" desvelava-
se como verdade. Pela primeira vez bramia a canção popular, demoniacamente
fascinante, em toda a ebriedade de um sentimento superpotente: o que
significava diante disso o artista salmodiante de Apolo (...) só timidamente
insinuados? O que antes era propagado em corporações poético-musicais, que se
dispunham em forma de castas, e era ao mesmo tempo mantido afastado de toda
participação profana, o que precisava permanecer, sob o poder do gênio
apolíneo, no nível de uma mera arquitetônica, o elemento musical, rejeitava aqui
todas as barreiras: a rítmica de antes, movendo-se no mais elementar ziguezague,
libertava os seus membros para a dança bacante: o som ressoava, não mais como
antes em fantasmagórica rarefação, mas sim com a sua massa mil vezes

${ }^{2}$ Ver Antonin Artaud - O Teatro e Seu Duplo - Editora Martins Fontes

${ }^{3}$ Ver Friedrich Nietzsche - A Origem da Tragédia - Proveniente do Espírito da Música - Editora Madras 
intensificada e como o acompanhamento de instrumentos de sopro de ressonância profunda. E o mais misterioso aconteceu: a harmonia, que em seu movimento leva a Vontade da natureza ao entendimento imediato, veio aqui ao mundo. Agora, as coisas em torno de Dioniso, que no mundo apolíneo jaziam veladas artificialmente, ganham som: todo o esplendor dos deuses olímpicos empalidecia diante da sabedoria do Sileno. Uma arte que em sua embriaguez extática dizia a verdade afugentava as musas das artes da aparência; no esquecimento de si dos estados dionisíacos dava-se o ocaso do indivíduo com seus limites e medidas; um crepúsculo dos deuses era iminente. (Nietzsche, 2005, p. 23-24)

Eurípedes, na tragédia Bacas ${ }^{4}$, como que parecendo responder a esta tendência de ruptura com o sentido de Dioniso na cultura grega, expõe em sua tragédia o fenômeno de seu mundo contemporâneo. $\mathrm{O}$ argumento do por que respeitar o culto a Dioniso traz uma "humanidade" e lógica desconectada do mistério, daquilo que é intangível ou intraduzível. Com a retórica aguçada, Tirésias tentará na tragédia justificar a manutenção de uma tradição estranha à pólis tebana governada por Penteu - naturalmente um assunto pertinente ao Teatro daquela época - a partir da finalidade ética e moral de seu culto.

Esse Nume novato de quem tu escarneces eu não poderia dizer quanta grandeza terá na Grécia, por que dois, ó jovem, princípios há entre os homens: Deméter Deusa ou Terra, chama-a pelo nome que preferes, ela com os sólidos nutre os mortais; este veio equivalente, o filho de Sêmele: úmido licor de uva inventou e apresentou aos mortais;dos sofridos homens ele cessa a dor quando se fartam do fluxo da uva, dá sono e oblívio dos males cotidianos, não há nenhum outro remédio das fadigas. Ele é libação aos Deuses, Deus nascido, de modo a terem os homens por ele bens. Tu ris de que ele se costurou na coxa de Zeus? Ensino-te como é bem isso. Quando o arrebatou do fogo fulminante, Zeus levou ao Olimpo o filhote Deus, Hera queria lançá-lo fora do céu; Zeus por sua vez tramou como Deus que é: quebrou côdea do fulgor circunterrestre e com ela fabricou entregando este Dioniso refém da cólera de Hera. Com o tempo mortais o dizem costurado na coxa de Zeus, mudando nome; porque o Deus para a Deusa Hera foi côdea refém, compuseram o conto. É adivinho este Nume, pois o báquico e o louco tem muita arte de adivinhar:

${ }^{4}$ Ver Eurípedes - Bacas tradução de Jaa Torrano - Hucitec 
quando o Deus vem pleno ao corpo faz os enlouquecidos dizer o futuro.

E tem alguma participação em Ares

Pois ao exército em armas e em ordem o pavor atordoou antes de tocar a lança.

É a loucura, e isso provém de Dioniso.

Ainda: hás de vê-lo nas pedras de Delfos

a saltar com tochas no chão dos dois cimos,

a vibrar e a sacudir o báquico ramo,

e grande na Grécia. Mas, Penteu, tem-me fé:

o poder não alardeie ter domínio dos homens

e, se nisso crês e essa crença te adoece,

não creias ter razão. Abre o país ao Deus

e liba e torna-te Baco e coroa a cabeça.

(Bacas,v. 272-313, p.64-65)

Porém, como que através uma escrita hermética ou órfica ${ }^{5}$, a prática teatral ajudou a manter, ainda que para iniciados na linguagem teatral, o culto a Dioniso. O debruçar sobre o sentido do trágico e da arte de imitar realizado em textos de Aristóteles, Platão e Nietzsche, trouxeram às claras ou estimularam uma possível re-significação, um sentido e uma contemplação do poder do fenômeno teatral dentro do espírito da sua tradição e consequentemente para o pensamento contemporâneo. Seja por um movimento de liberação, de catarse ou de louvor ao bode, a máscara de Dioniso acaba se "presentificando" ainda hoje em nossos palcos.

A escolha de uma tradução que revele este espírito pode ajudar ao exercício da experiência dionisíaca no teatro. $O$ texto que segue se propõe a apresentar algumas justificativas do exercício cênico com a tradução Bacas - 0 mito de Dioniso, realizada pelo professor Jaa Torrano a partir da consciência que seus textos trazem sobre o significado sagrado de Dioniso. Trata-se de uma obra que permite adentrar no universo dionisíaco através das palavras, mas, antes das palavras, pelas suas musas e memórias.

\section{As Musas, a memória e a experiência estética}

Pelas Musas heliconíades comecemos a cantar

Elas têm grande e divino o monte Hélicon, em volta da fonte violácea com pés suaves dançam e do altar do bem forte filho de Cronos.

(...)

Na Piéria gerou-as, da união do Pai Cronida

\footnotetext{
${ }^{5}$ Ver Detienne, Marcel. A escrita de Orfeu. Jorge Zahar Editor, p.115: "Caberia a uma sociologia da cultura ensinar-nos em sua linguagem que a mitologia, com ou sem mito, tem para nós a autoridade de um fato natural, enquanto há tanto tempo - dois s'́culos no mínimo - a filosofia, a história das religiões e a última semiótica se revezam a procura de uma essência fugitiva e inapreensível do mito."
} 
Memória rainha nas colinas de Eleutera,

Para oblivio de males e pausa de aflições.

Nove noites teve uniões com ela o sábio Zeus

Longe dos imortais subindo ao sagrado leito.

Quando girou o ano e retornaram as estações

Com as mínguas das luas e muitos dias findaram,

Ela pariu nove moças concordes que dos cantares

têm o desvelo no peito e não-triste ânimo,

perto do ápice altíssimo do nevoso Olimpo,

aí os seus coros luzentes e belo palácio

(...) nove filhas nascidas do grande Zeus:

Glória, Alegria, Festa, Dançarina,

Alegra-coro, Amorosa, Hinária, Celeste

E Belavoz, que dentre todas vem à frente.

(Teogonia , Tradução de Jaa Torrano,1995.)

O coro das musas produz "oblívio dos males e pausa de aflições", as nove filhas de Zeus e da Memória têm o talento de aliviar o sofrimento e causar alento, seus nomes traduzidos aqui revelam as qualidades que cada uma possui e assim, a experiência estética que pode produzir um dos maiores alentos: o conhecimento, porque este permite a troca, a percepção e o caminho para a sabedoria.

Segundo o Livro I da Metafísica de Aristóteles, o primeiro estágio do saber se dá pela via dos sentidos. Hoje, a pedagogia e a educação moderna reafirmam esta perspectiva e chegando a considerar a experiência sensível paradigmática (BOIS, 2008). A partir primeiramente da experiência sensível algo se move no campo cognitivo e a partir de um processo de elaboração da memória daquilo que foi percebido ou experienciado se tornará saber. Caso tenha o sujeito despertado para a "curiosidade epistemológica" (FREIRE, 2004) a partir da experiência estética o seu saber por fim se traduzirá novamente em uma expressão estética: a linguagem que é a que permitirá a compreensão e a democratização da experiência adquirida.

Quanto mais me torno rigoroso na minha prática de conhecer tanto mais, porque crítico, respeito devo guardar pelo saber ingênuo a ser superado pelo saber produzido através do exercício da curiosidade epistemológica. (Freire, 2004, p. 64)

$\mathrm{Na}$ apreensão da experiência sensível é fundamental a Memória. Esta estabelece o sentido e que faz o contato entre obra e espectador, algo que se traduz em linguagem: a palavra. No ensaio de Jaa Torrano publicado em sua tradução da Teogonia de Hesíodo percebemos seu olhar sobre o sentido mítico da palavra, sua presença que possui relação direta com algo inerente ao humano e que para a cultura grega trazia a concretude do mito, algo que as artes por si só trazem e são para além dos significados e leituras que possamos ter. 
A Linguagem, que é concebida e experimentada por Hesíodo como uma força múltipla e numinosa que ele nomeia com o nome de Musas, é filha da memória, ou seja: deste divino Poder trazer à Presença o não-presente, coisas passadas ou futuras. Ora, ser é dar-se como presença, como aparição (alethéa), e a aparição se dá sobretudo através das Musas, estes poderes divinos provenientes da Memória. (Torrano, 1992, p. 29)

As artes promovem um contato estético com o indivíduo, lidam justamente com uma esfera que pretende o despertar e nisso nós, os artistas, somos agentes, somos atores. Quando nos expressamos somos músicos, atores, dançarinos, performers, artistas plásticos, educadores, produtores, cultivadores e utilizamos inúmeras técnicas e tecnologias que no contato dialógico de nossa relação com o outro, de forma mais ou menos sutil, comunicamos artisticamente e revelamos um saber que pode ser apreendido por esse outro. Assim o campo artístico é um campo de saber e de ciência.

No momento em que a memória é acionada e constrói o sentido, se dá a reminiscência, a memória que se apresenta para construir aquele sentido vivenciado. Desta forma, o sentido musical, o sentido cênico ou de maneira geral, o sentido estético só se constrói porque há a retenção na memória de algo que foi ouvido ou visto, ou mais: experimentado - algo que foi sentido em seus múltiplos sentidos.

Aqui temos um primeiro desafio para o ator ao interpretar Bacas: para um artista alcançar a potência de sensibilizar o outro ele de fato deve, em algum momento, ter adquirido um saber para transmitir ou para expressar? Há um saber implícito e um modo técnico para que isso aconteça?

A princípio considera-se que o artista deveria ter um domínio de códigos expressivos que potencializassem e maximizassem a recepção do espectador, ou que o mobilizam naquilo que Augusto Boal chama de Espectator. Ainda que não seja um processo plenamente racionalizado ou plenamente intuitivo, questão que se apresenta de forma consistente no Paradoxo do Comediante de Denis Diderot, existe um saber que possibilita ao ator a expressão do que deseja através da linguagem artística. Assim, aquele que profere a palavra já de alguma forma a detém, mesmo que não tenha exata consciência disto antes que a própria experiência se realize.

A percepção de diferentes graus de diversão, de prazer, proporcionados pela experiência estética são diversos tanto para quem faz quanto para quem pensa ser apenas espectador. Não cabe aqui um juízo de valor de qual prazer estético é melhor ou pior, muitos são os condicionantes culturais que nos fazem ver apenas aquilo que nos parece melhor a partir de nossa própria perspectiva. Assim por exemplo, na cultura popular brasileira, os mestres das folias e os foliões dos espetáculos dramáticos: Bumba-meu-boi, Boi de Mamão, Folia de reis, Caixeiras do Divino carregam o espírito de Dioniso. 
Esses são de alguma forma Bacos - suas cenas e rituais repletos de cantos em linguagem popular e simples são paradoxalmente distantes da compreensão racional pois afetam uma região do sensível que é praticamente intangível. Como nos diz Nietzsche na Origem da Tragédia:

\begin{abstract}
Na Idade Média (alemã) também se celebravam, sob idêntica força dionisíaca, hordas sempre crescentes, cantando e dançando de uma parte a outra. Nestes dançarinos de São João e de São Vito percebemos os coros báquicos dos gregos com sua pré-história na Ásia Menor, até na Babilônia e aos sakéos entusiastas. Há homens que, por falta de conhecimento ou por estupidez, se afastam de tais aparecimentos como de "doenças populares" ironizando-as ou as lamentando, no sentir da própria saúde: estes pobres não suspeitam de como se torna lúgubre e fantasmagórica esta sua saúde, quando por eles passa, atribulada, a vida ardente de entusiastas dionisíacos. (2005, p. 27)
\end{abstract}

"Bacas - O Mito de Dioniso", estudo e tradução de Jaa Torrano, é referência para qualquer proposta de encenação do texto de Eurípedes. Por se aproximar com rigor linguístico ao espírito que a obra de Eurípedes queria revelar a seus contemporâneos, tal tradução é para o público contemporâneo uma fonte de conhecimento iniciático. No entanto, onde o universo linguístico aparentemente a tornaria distante do público do ponto de vista intelectivo, pois traz palavras que fogem à linguagem cotidiana, revelam aspectos sensíveis para provocar a compreensão do iniciado. A experiência estética a ser realizada com a sonoridade e o sentido do texto são parte do trabalho dos atores, dos técnicos e do grupo teatral, amador ou profissional, que transponha a tradução do texto trágico para a cena - o que exigirá um tanto considerável de dedicação ao ofício.

Ao preparar a encenação de Bacas de Eurípedes, como um texto a ser colocado em cena nos dias de hoje, a partir da escolha de uma tradução como esta, é preciso considerar a distância de tempo e de cultura. São aspectos presentes na cultura grega clássica com nuances próprias para a relação com o mito de Dioniso e com quem Eurípedes está dialogando. No entanto, o texto atravessa o tempo e nos diz algo ainda hoje e que só pode ser compreendido quando nos apropriamos da experiência sensível em nosso próprio contexto cultural: local e temporal. Não se trata de realizar e dizer o texto como se o fizéssemos no século $\mathrm{V}$ a.C. e sim para os dias de hoje, para o público de hoje.

Esta obra presentemente desvela aspectos de Dioniso, de seu mito e de seu culto e traz nesta tradução a força e presença de um texto dramático clássico com grande potência trágica e poética. A tradução de Jaa Torrano prima pela experiência estética pela sonoridade que as palavras produzem, mas sobretudo, pelo efeito dado pela precisão em seus significados.

Eia, Bacas! Eia, Bacas!

Brômio Deus filho de Deus, 
Dioniso, vinde trazê-lo, das montanhas frigias para as amplas ruas

da Grécia, o Brômio (...)

Esse pode ser um dos impulsos para encenar essa obra em nossos dias: o desejo de encontrar elementos mais profundos por trás dos próprios fundamentos do teatro, considerando as palavras deste texto um rico documento sobre o espírito e as práticas de culto a Dioniso, através desta arte àquele que é o Deus do Teatro.

Sobre esta tradução parece imperar o propósito de revelar, aos que quiserem e puderem se inteirar, uma experiência com o "caráter esotérico" da obra de Eurípedes, tal como é proposto por Jaa Torrano quando cita Maurice Lacroix:

A concepção religiosa de Eurípedes, tal qual as Bacas nos parecem revelar, tem um caráter esotérico. Só os iniciados de alma pura podem ter acesso a esta altitude; os outros agirão sabiamente conformando-se com as idéias recebidas por seus contemporâneos. (1992)

O texto dramático, ainda que contenha uma grande potência enquanto literatura só se revela como tal para aquilo que foi escrito para a ação, pressupõem, portanto, os atores. Estes, na experiência com as palavras, precisam ter consistência nas palavras proferidas e na ação realizada. De que forma isso pode ser feito com o texto Bacas? Isto requererá evidentemente uma concepção pessoal que será apresentada e que denota o motivo da escolha desta tradução e exigirá dos atores certo conhecimento do que significam elementos da prática Dionisíaca que Eurípedes relata afim de que as palavras e as ações não se esvaziem de sentido.

Jaa Torrano lista alguns traços do pensamento mítico e que parecem ser precisos para quem quer realizar uma performance viva para o público contemporâneo são eles: oralidade; concretude; a importância dos nomes divinos e da palavra em geral; o repertório de sinais divinos; e, o nexo necessário entre verdade, conhecimento e existência.

\section{Memória pessoal de um bacante}

O teatro, de certa maneira, propõe a seus praticantes um contato com os mistérios báquicos quando propõe aos que o praticam a oportunidade de ser Baco. Trarei com o fim de exemplificação, relatos pessoais de uma experiência com a natureza e o sentido do ofício teatral sobre o Mito de Dioniso e que tangerá a presença do espírito dionisíaco na prática cênica que considero viva, uma experiência pessoal que é exigida para uma prática 
consistente sobre o texto e que esbarra na pergunta de Penteu a qual Dioniso responde: "A mortais não-Bacos é interdito saber."

Ao final de 2005, tive renascido o prazer teatral quando reconheci o espírito dionisíaco que movia o meu fazer artístico para além da profissão. A partir de algumas experiências pude compreender aspectos sutis do trabalho artístico e daí, fez um sentido especial o convite feito por uma coreógrafa de comissão de frente, bailarina e pesquisadora acadêmica, Yáskara Manzini ${ }^{6}$, para que dirigisse a ação cênica de atores no carro abre-alas da Camisa Verde Branco no Carnaval Paulistano. Poderia ser mais um trabalho que exerceria apenas profissionalmente, se naquele ano o tema da escola não fosse Dioniso e eu não tivesse disposto a abrir-me como amador para compreender a força entheógena que ali se traduzia.

No dia 26 de fevereiro de 2006, apresentávamos o resultado do trabalho que teve como consequência uma considerável visibilidade midiática: foi matéria de uma das capas das edições $O$ Estado de São Paulo ${ }^{7}$ daquele dia e resultou em uma chamada ao vivo na Rede Globo de Televisão naquela madrugada - e nós atores-Bacos, estávamos acordados e alegres por termos colaborado com a ascensão da escola de samba através de nossa performance. $O$ desfile, que terminou por volta das 3 horas da madrugada, conseguiu empolgar uma plateia já sonolenta com os atores realizando uma performance bacante, presente e intensa, em um carro que exalava cheiro de vinho e o teor sensual do jogo dos atores atraía os olhares eróticos do público: Eros participa dos cortejos Dionisíacos. O trabalho de diretor de cena foi fundamentado em uma intensa pesquisa teórica e prática, que envolvera a mim e o grupo de atores sobre Dionisismo. O estudo de "Bacas - O Mito de Dioniso" servira de fundamento para o grupo.

O primeiro contato com a obra de Jaa Torrano se deu pela sua tradução de Teogonia de Hesíodo, pela Editora Iluminuras, na década de 1990. A precisão e a força das palavras, as imagens que elas traduziam, suscitavam-me graus de compreensão que iam para além da mera compreensão da narrativa, envolviam-me na poesia. Além do mais, por trás das palavras, havia a revelação do espírito de um povo, de uma cultura. Tal experiência, estética e iniciática, se repetira com a tradução de Bacas. (Depoimento)

A prática partia de uma série de leituras ativas de Bacas, leituras que se propõem a transpor elementos teatrais com aspectos que estão contidos nos traços que Jaa Torrano observa no pensamento mítico, citados anteriormente.

A partir do jogo dos atores sobre estas experiências percebeu-se mesmo a sonoridade musical das palavras e cujo entendimento e compreensão vinham muito do vigor e consciência do que estava sendo dito para realizar uma corporeidade que emanaria dos atores e que chamarei de presentificação do texto escrito.

Naquele mesmo dia, em uma tarde de carnaval, após toda esta experiência atendi ao convite de um dos atores para assistir pela primeira vez o ensaio

6 Yáskara Manzini é Doutora em Artes pela UNICAMP e desde antes de 2006 já fazia a coreografia da Comissão de frente do Camisa Verde Branco

${ }^{7}$ Naquele dia o jornal tinha tido mais de uma edição. 
aberto do grupo Uzyna Uzona, do Teatro Oficina, sob a direção de Zé Celso Martinez Correia. Tratava-se de um dos grandes atos de "Os Sertões" de Euclides da Cunha. Assim a experiência dionisíaca se completava após 5 horas de celebração que acontecia no formato de ensaio aberto, vi um teatro que era vivo e não era apenas forma. Vislumbrei atores que cantariam e tocariam, ao mesmo tempo que exerceriam uma postura de performer com um corpo de expressividade dilatada mas plenos de si e comunicando-se com o público com o repertório estabelecido colocando-se aqui como atores, podendo inclusive despertar o ator no espectador. Experimentei algo como o que é descrito pela diretora teatral Cibele Forjaz em um seminário no Agora Teatro em São Paulo:

É verdade que muita coisa se transformou desde lá. Eu também fiz ECA, e o fato é que, quando eu vi As Boas (1991) [peça de Jean Genet protagonizada por Zé Celso e Raul Cortez], eu levei um soco no estômago e achei que tudo o que eu tinha visto ou feito não tinha mais sentido. Entrei em crise...Eu já tinha dirigido vários espetáculos, inclusive um Woyzeck; mas eu entrei em crise total, parei...Foi a primeira vez que eu vi alguém olhar para a platéia e falar com quem estava sentado, e o que o Zé [Celso] dizia, o que o Marcelo [Drummond] dizia, o que o Raul [Cortez] dizia era imediatamente para aquelas pessoas ali, naquele momento. Não era um teatro nem estético...Era uma bagunça, totalmente diferente do que eu tinha visto até então, muito bonito, e eu percebi que o teatro não era aquilo que eu tinha estudado, aquilo que estava se fazendo - eu levei um soco no estômago. Entendi ali que o teatro só interessa se ele for para os nossos contemporâneos, para as pessoas que estão ali presentes, construindo o mundo em que vivem (...) (ÁGORA TEATRO p.96)

Ao final eu e alguns poucos que chegaram ao final da experiência ficamos para cumprimentar Zé Celso, eu, por minha vez, pedi sua benção, ao que Zé Celso convidou-me para trabalhar como seu secretário. (Depoimento)

Durante alguns dias que durou esta experiência com Zé Celso pude imergir em um universo profundamente dionisíaco. Junto com Zé Celso, naqueles dias, li experimentando a presentificação: Fedro de Platão, as cenas de Penteu e Dioniso, de "As Bacantes" traduzida por Zé Celso e Invocação a Pan traduzida por Fernando Pessoa do texto de Aleister Crowler. pelo que chamo hoje o Uzyna Uzona de um tíaso animado pelo representante do "regente Brômio": Zé Celso Martinez Correia. Foi realmente uma experiência fundamental para começar a compreender um novo universo teatral.

O estudo a fim de realizar plenamente a encenação das Bacas após esta experiência frutificara até então apenas com amadores no trabalho com pacientes psiquiátricos do Centro de Atenção Psicossocial Itapeva, em uma experiência limítrofe onde se discutia a loucura que provoca a dor e a loucura sagrada. Os pacientes envolvidos em um projeto voluntário de teatro dentro da prática antimanicomial foram atraídos pela experiência que considerava não como uma doença o seu estado, mas como uma outra natureza de percepção e significação. Com a participação de atores amadores e apenas um profissional 
o projeto foi realizado e dois dos pacientes tiveram alta logo depois, não necessariamente em decorrência deste trabalho, pois talvez eles tivessem optado por participar justamente por já estarem perto da própria "sanidade".

Em relação a "Bacas" havia ainda de realizar o propósito de aprofundar o sentido da "arqueologia cultural" num grau profissional para possibilitar ao público se aproximar de uma experiência com a compreensão dos símbolos, signos e valores de cada elemento surgido no texto que uma prática experiente consegue revelar com mais vigor. Trata-se de significados que vão se revelando na escolha e na conformidade das palavras com o espírito pulsante da obra. Há algo mais do que uma escolha poética, há um estudo, uma investigação, uma presença musical na obra produzida em língua portuguesa e que o ator deve conseguir revelar. Daí resta o desafio: revelar o texto.

Todo esse processo precisa agora incorrer na aplicação das teorias de "leitura ativa" e de "presentificação" justamente para realizar o texto de Jaa Torrano na íntegra, apropriando-se das suas opções de tradução, de sua força poética e precisão sem adaptações ou cortes, e ainda assim dar a compreender a completude e a complexidade da obra a ser trabalhada por toda a equipe que estiver envolvida na encenação.

Através da "Leitura ativa", tomar o texto com a cultura que possuímos em nosso mundo contemporâneo e com uma verdade que olha o entorno construindo sentido para as palavras. E da "presentificação", realizar uma interpretação orgânica que se aproprie das experiências verdadeiras que temos durante a performance e que nos fazem potencializar a oralidade e a concretude, valorizar de fato os sinais e nomes que surgem na ação dramática.

O impulso que move alguém de teatro para a prática teatral sobre esta obra traduzida e original, que refletirá aspectos da presença Dionisíaca em seus cultores - atores e homens de teatro, que na sua origem o eram e que nos dias de hoje têm essa consciência e encenando essa obra buscarão formas de traduzir cenicamente essa experiência de trazer Dioniso à cena.

Assim, a investigação e o processo teatral sobre as Bacas se constrói de acordo com os auspícios e com a vontade, exigindo a maturidade de todo um conjunto de processos, de conhecimento e compreensão do sentido e da experiência com o mito e com o texto afim de não esvaziar seu sentido e de potencializar a experiência do público no encontro com o próprio mito dionisíaco.

Recebido em 15 de Julho de 2013. Aceito em 24 de Novembro de 2013. 


\section{REFERÊNCIAS}

ANDRADE, Mario de. Ensaio sobre a música brasileira. São Paulo: Livraria Martins Editora/MEC,1972.

ARTAUD, Antonin. O Teatro e seu Duplo. São Paulo: Martins Fontes, 2008.

Ágora Teatro. Teatro Paulistano no séc.V. São Paulo, Ágora Teatro, 2006. Entrevista com Cibele Forjaz (Cia. Livre) e Georgette Fadel (Cia. São Jorge de Variedades)

BOAL, Augusto. Técnicas Latino Americanas de Teatro Popular - Uma revolução copernicana ao contrário. Centelho, Coimbra,1977. p.24

DETIENNE, Marcel. A Escrita de Orfeu. São Paulo: Jorge Zahar Editor, 2003.

FREIRE, Paulo. Pedagogia da autonomia. São Paulo, Paz e Terra, 2009.

NIETZSCHE, Friedrich. A Origem da Tragédia. São Paulo: Madras,2005

. A Visão Dionisíaca do Mundo. São Paulo, Martins Fontes,2005.

NORONHA, José Renato. Entre o Templo e a Encruzilhada. Dissertação de Mestrado, Faculdade de Educação, UNICAMP, 2002.

PLATÃO. Fedro.São Paulo. Editora Martin Claret,2005.

TORRANO, Jaa Teogonia - A origem dos deuses. São Paulo: Iluminuras projetos e produções editoriais, 1992.

WISNIK, José Miguel - O som e o sentido - uma outra história das música. São Paulo: Companhia das Letras, 2006. 